Social Epistemology

\title{
A Virtue Epistemology of the Internet: Search Engines, Intellectual Virtues and Education
}

\section{Richard Heersmink}

To cite this article: Richard Heersmink (2018) A Virtue Epistemology of the Internet: Search Engines, Intellectual Virtues and Education, Social Epistemology, 32:1, 1-12, DOI: 10.1080/02691728.2017.1383530

To link to this article: https://doi.org/10.1080/02691728.2017.1383530

$$
\text { 册 Published online: } 27 \text { Oct } 2017 .
$$

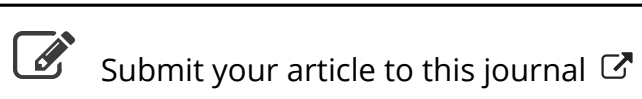

Џll Article views: 58

Q View related articles $\asymp$

View Crossmark data $\nearrow$ 


\title{
A Virtue Epistemology of the Internet: Search Engines, Intellectual Virtues and Education
}

\author{
Richard Heersmink \\ Department of Philosophy, Macquarie University, Sydney, Australia
}

\begin{abstract}
This paper applies a virtue epistemology approach to using the Internet, as to improve our information-seeking behaviours. Virtue epistemology focusses on the cognitive character of agents and is less concerned with the nature of truth and epistemic justification as compared to traditional analytic epistemology. Due to this focus on cognitive character and agency, it is a fruitful but underexplored approach to using the Internet in an epistemically desirable way. Thus, the central question in this paper is: How to use the Internet in an epistemically virtuous way? Using the work of Jason Baehr, it starts by outlining nine intellectual or epistemic virtues: curiosity, intellectual autonomy, intellectual humility, attentiveness, intellectual carefulness, intellectual thoroughness, open-mindedness, intellectual courage and intellectual tenacity. It then explores how we should deploy these virtues and avoid the corresponding vices when interacting with the Internet, particularly search engines. Whilst an epistemically virtuous use of the Internet will not guarantee that one will acquire true beliefs, understanding or even knowledge, it will strongly improve one's information-seeking behaviours. The paper ends with arguing that teaching and assessing online intellectual virtues should be part of school and university curricula, perhaps embedded in critical thinking courses, or even better, as individual units.
\end{abstract}

\section{KEYWORDS}

Virtue epistemology; intellectual virtues; Internet epistemology; cognitive skills; search engines; education

\section{Introduction}

The Internet is an important epistemic source. Our information-seeking behaviours often involve Internet applications such as search engines, blogs, social media, online encyclopaedia, maps and databases. This has changed the way we access and consume information, deeply transforming the way we think, act and remember (Smart, Heersmink, and R. Clowes 2017b). The Internet generally provides its users with more epistemic benefits than drawbacks (Heersmink 2016; Smart, Clowes, and Heersmink 2017a); however, unreflexively using Internet-based sources poses epistemic risks for information-seeking and knowledge acquisition. For example, critics point out that search engines may prioritise false or misleading information in search results (Lynch 2016), generate filter bubbles and lead to confirmation bias due to personalised ranking of search results (Simpson 2012; Miller and Record 2013), and sometimes suggest autocompleted search terms that may nudge one towards a wrong path of enquiry (Miller and Record 2016). Also, information on blogs, social media and Internet forums is sometimes posted by anonymous non-experts, which makes it hard to verify the validity of the source. ${ }^{1}$ Some of these issues remain open questions and can be circumvented, but they do imply that we should be cautious 
with unreflexively using search engines and the Internet. Given these possible epistemic drawbacks, an important question to ask is: How to use the Internet in an epistemically virtuous way? I shall answer this question using a virtue epistemology approach. Focussing on an agent's cognitive character and agency, it is a fruitful but underexplored approach to using the Internet in an epistemically desirable way (but see e.g. Choo 2016).

This paper has the following structure. I first outline virtue epistemology, particularly virtue responsibilism, and the notions of intellectual virtues and vices. I then present some of the Internet's functional and informational properties, and briefly survey the recent debate on Internet epistemology with a focus on search engines. Having a basic grasp of the notion of intellectual virtue and some of the epistemic properties of the Internet, I examine which intellectual virtues we should cultivate and deploy when epistemically interacting with the Internet, particularly search engines. I end this paper by arguing that we should teach online intellectual virtues (or Internet literacy skills) to our students. We should also change our assessment regimes as to allow students, at least in some cases, access to the Internet when making their exams. It is important that we change our educational policies because the Internet literacy skills of most people (in both Western and non-Western cultures) are underdeveloped (van Deursen and van Dijk 2010), which has detrimental consequences for our information-seeking behaviours.

\section{Virtue Epistemology}

\subsection{Introduction}

Virtue epistemology is a set of approaches in contemporary epistemology, giving epistemic or intellectual virtues a central role (Battaly 2008). Two species can be identified: virtue responsibilism and virtue reliabilism. The difference between these species concerns the way they characterise the nature of intellectual virtue. Virtue responsibilism characterises intellectual virtues as acquired or learned cognitive character traits such as curiosity, intellectual autonomy and open-mindedness. These have been referred to as trait-virtues. Virtue reliabilism, by contrast, characterises intellectual virtues as more or less stable cognitive faculties such as vision, introspection and memory. These have been referred to as faculty-virtues (Greco and Turri 2011). Given that this paper is about an epistemically virtuous use of the Internet, the focus will be on virtue responsibilism, as learned intellectual character traits (such as, for example, intellectual autonomy) seem more relevant when interacting with the online world. This is so, partly because they are more malleable and open to education. I am not implying that faculty-virtues are not relevant when using the Internet. Vision and memory, for example, are clearly important when using the Internet for epistemic purposes (see Michaelian and Arango-Muñoz forthcoming for an analysis of reliabilist virtues in relation to technology). The goal of this paper is not to enter the debate between virtue reliabilism and responsibilism nor to prioritise one over another. Rather, its goal is more practical, that is, to explore and conceptualise the value of certain intellectual virtues when interacting with the online world.

Virtue epistemology is less concerned with the nature of truth and more concerned with the cognitive character of agents. Compared to traditional analytic epistemology, 'virtue epistemology takes intellectual virtues and vices - types of agent-evaluation - to be more fundamental than justification, knowledge, or any other type of belief-evaluation' (Battaly 2008, 640). Virtue epistemology is thus agent-based, rather than belief-based. In her book, Virtues of the Mind, Zagzebski (1996) claims that knowledge and justified belief result from being intellectually virtuous. She writes:'knowledge is a state of cognitive contact with reality arising out of acts of intellectual virtue' (Zagzebski 1996, 270). Thus, on her view, if an agent is intellectually virtuous, then knowledge will automatically follow from the agent's cognitive acts. My view is that this will clearly increase the likelihood of knowledge acquisition, but will not guarantee it. Even an intellectually virtuous agent will sometimes obtain false beliefs.

Essentially, virtue epistemology is about improving one's cognitive skills, rather than the nature of truth or justification. Virtue epistemology is thus normative; it is concerned not so much with how we think but with how we should think. Its goal is stipulating and promoting how to think well. In 
comparison, the goal of virtue ethics is to provide a framework for living an ethically virtuous life. Likewise, the goal of virtue epistemology is to provide a framework for living an epistemically or intellectually virtuous life. For this reason, some virtue epistemologists focus on education (e.g. Baehr 2013, 2015a; Pritchard 2013; Battaly 2016), as we must learn how to become intellectually virtuous and flourish as thinkers. We must also learn how to use the Internet in an epistemically responsible way and so it seems a natural fit to apply a virtue epistemology approach to Internet use.

Before discussing several intellectual virtues of the responsibilist stripe, it is helpful to get some clarity on their nature. Baehr (2015b) outlines four dimensions of intellectual virtues: a motivational dimension, an affective dimension, a competence dimension and a judgement dimension. First, an agent must be intrinsically motivated to achieve some epistemic goal such as knowledge, truth or understanding. If an agent is thorough and rigorous only to impress her peers or to avoid losing her job, then the agent in question is not virtuous in the relevant sense. An agent must thus be motivated to achieve an epistemic goal for its own sake. Second, when pursuing one's epistemic goals, an intellectually virtuous agent experiences some level of pleasure, fulfilment or even excitement. Conversely, an intellectually virtuous inquirer may feel regret when he or she has made a mistake. An intellectually humble agent, for example, will acknowledge the mistake and may feel regret or some discomfort. Third, an agent must be cognitively competent in achieving one's epistemic goals, which often requires training and practice. As Baehr points out, an open-minded agent will set aside a default cognitive standpoint in order to take up an alternative one, an attentive agent will notice and attend to important details, a curious agent will ask thoughtful and insightful questions. Finally, an intellectually virtuous agent has an awareness of which virtues should be used in which situation. Understanding how one achieves one's epistemic goals requires judgement on part of the cognizer.

\subsection{Intellectual Virtues}

Intellectual virtues are cognitive character traits that are truth-conducive and minimalise error. In his book, Cultivating Good Minds, Baehr (2015a, but see also his 2011) provides an elaborate analysis of nine intellectual virtues. He groups them in three helpful and intuitive categories. First, virtues required for getting the learning process of the ground: curiosity, intellectual autonomy and intellectual humility. Second, virtues required for keeping the learning process on the right track: attentiveness, intellectual carefulness and intellectual thoroughness. Third, virtues for overcoming obstacles to productive learning: open-mindedness, intellectual courage and intellectual tenacity. Below I provide a concise overview of these virtues.

(1) Curiosity: Curious people want to explore and broaden their epistemic horizons. Someone who is curious is intrinsically motivated to learn new knowledge. A curious person is disposed to wonder and to ask why things are the way they are. He or she is genuinely motivated to get a deeper understanding of a certain topic, concept or event, not because of some extrinsic reason, but because of a 'love' of knowledge (see also Roberts and Wood 2007).

(2) Intellectual autonomy: This virtue can be characterised as a willingness and ability to think for oneself. Someone who is intellectually autonomous is cognitively capable and does not depend (a lot) on others for acquiring her beliefs. Such agents further have a healthy dose of scepticism and when faced with disagreement do not immediately capitulate by changing their mind. This, of course, does not mean that one is stubborn; one should also be realistic about one's cognitive skills and accept authority and experts when appropriate.

(3) Intellectual humility: This virtue is about admitting and being aware of one's cognitive limitations, weaknesses and mistakes. An intellectually humble person is aware of what he does not know, of which of his reasoning skills need improvement and of the kinds of reasoning mistakes to which he is prone. In such cases, he is realistic about intellectual and knowledge domains that are not his strengths. 
(4) Attentiveness: People who are attentive pay close attention and focus on the task at hand. An attentive person has a sustained focus when performing some cognitive task, say, writing an essay or reading a text. He or she has a sustained attention to important details, and processes these details in an adequate way. Baehr points out that attentiveness is one way in which curiosity is sustained and applied.

(5) Intellectual carefulness: This virtue is about avoiding intellectual errors or mistakes, including false beliefs and ignorance. Note that there is a distinction between acquiring true beliefs and avoiding false beliefs. To be able to avoid mistakes, one needs to know what a mistake is and have a sensitivity of in which situations common mistakes are made. A grasp of basic logic and critical thinking skills, as these relate to specific knowledge domains, are necessary to avoid mistakes.

(6) Intellectual thoroughness: An intellectually thorough person is disposed to probe for deeper meaning and understanding. Such a person will not be satisfied with a superficial or cursory accounts of things. He or she will keep thinking about a particular topic or concept until s/ he has a firm grasp and understanding of it. An intellectually thorough person aims for an explanation of the phenomenon in question, and does not just accept some statement. She will not be satisfied with merely memorising a set of isolated statements but wants to be able to draw connections between different units of information.

(7) Open-mindedness: An open-minded person is willing to consider alternative views, and if these seem more accurate or well founded, then she is willing to change and revise her initial beliefs. This is epistemically beneficial because it allows us to form the best, most reasonable and most accurate beliefs we can. Of course, this doesn't mean that we shouldn't have firm beliefs, only that if there are better views and beliefs available, we should be open to change our own views. Ideally, we have an awareness of which domains of knowledge we are knowledgeable about and of which domains we are less knowledgeable about. We should be more open to change our views in domains that are not our strengths, as compared to domains that are our strengths.

(8) Intellectual courage: Baehr describes this virtue as subjecting ourselves to a potential loss or harm in the context of a distinctively intellectual pursuit like learning or inquiring after the truth. For instance, it takes intellectual courage when someone contributes to a class discussion when that person is not completely sure of her contribution and may feel some embarrassment if she is indeed wrong. A key example in the history of science is the publication of Galileo Galilei's book, Dialogue Concerning the Two Chief World Systems, when he knew there could be repercussions from the church.

(9) Intellectual tenacity:The final virtue can be described as persistence or perseverance. Someone who is intellectually tenacious doesn't give up quickly when he doesn't understand something. $\mathrm{He}$ is also not easily deterred by initial failure in his inquires. Even when an inquiry is challenging, he keeps pursuing his epistemic goals. Typically, a person who is genuinely curious about some topic, will persist until he has achieved his epistemic goal.

What all these virtues have in common is that they are character traits that a person who desires truth and understanding would want to have. My view is that there is some overlap in these intellectual virtues, and depending on the epistemic situation, some of these may be more important than others. Also, other virtue theorists (e.g. Roberts and Wood 2007) have proposed (slightly) different intellectual virtues and so Baehr's list is not meant to be exhaustive. It does, however, provide a solid starting point for exploring how we should use the Internet in an intellectually virtuous way.

\subsection{Intellectual Vices}

Intellectual vices are cognitive character traits that are not truth-conducive and do not minimalise error. As Aristotle points out in the Nicomachean Ethics, there is a vice associated with each moral virtue. The same is true for intellectual virtues. There is thus a vice for every virtue outlined above, which are 
opposites of virtues. So, the opposite of curiosity is intellectual apathy, the opposite of autonomy is dependence, the opposite of humility is arrogance, the opposite of attentiveness is neglect or inattention, the opposite of carefulness is carelessness, the opposite of open-mindedness is being dogmatic, the opposite of intellectual courage is intellectual conformity and the opposite of intellectual tenacity is indecisiveness. To be a bit more precise, a virtue is a mean between two vices. Open-mindedness, for example, lies in the mean of the vices of dogmatism and naivety. A dogmatic person will consider too few alternatives and ignore too many, a naïve person will consider too many and ignore too few (Battaly 2016). An open-minded person will consider the right number of alternatives.

\section{Internet Epistemology}

Before I look at some intellectual virtues and vices in relation to the Internet, it is helpful to have a basic grasp of the Internet and some of its functional and informational properties. On their website, the authoritative WWW Consortium defines the World Wide Web as 'an information space in which the items of interest, referred to as resources, are identified by global identifiers called Uniform Resource Identifiers (URI)'. In this paper, I use the term 'Internet' as a catch-all term for all the various applications that are built on top of the Internet. This includes the Web, which is currently the most popular Internet application. From an epistemic perspective, the most salient dimension of the Internet is that it is an information space. The information it contains is usually presented on websites, typically containing hypertext, but also images and videos, in which hyperlinks are used to navigate between different websites. The Web functions as a layer on top of the Internet, which is a system of many interconnected computer networks. Thus, the Internet is the physical infrastructure on which the Web runs, so to speak.

In previous work (Heersmink 2016), I argued that 'in an information society such as ours, having the skills to efficiently navigate, evaluate, compare, and synthesise online information are typically more valuable than having a lot of facts stored in biological memory' (Heersmink 2016, 389). In the next section, I elaborate on this claim by adopting a virtue epistemology approach. My initial view was developed in response to critics such as Carr (2011) and Greenfield (2014) who claim that the Internet makes us cognitively and epistemically less competent. Echoing Socrates's criticism on written language, they argue that relying on search engines and online encyclopaedia results in storing fewer facts in our longterm biological memory. This is epistemically undesirable because it implies that (heavy) Internet users know less. My view is that even if using the Internet results in storing fewer facts in biological memory, which I don't think has been empirically established yet (Heersmink 2016), it may be compensated by having reliable access to the world's most extensive and powerful information source. If we know how to use the Internet in an epistemically virtuous way, then it seems to me that we gain more than we lose in terms of epistemic goods.

Thagard (2001) evaluates the epistemic value of the Internet using Alvin Goldman's criteria of reliability, power, fecundity, speed and efficiency. Thagard analyses how the Internet contributes to scientific research, concluding that the Internet ranks high on all of Goldman's criteria and therefore positively contributes to the generation of scientific knowledge. I agree with Thagard's approach and conclusion; however, the analysis in this paper is broader and concerns not the generation of scientific knowledge, but is more focused on the cognitive properties of agents than of the Internet. My approach is also related to but significantly different from Smart's (forthcoming). Smart analyses the Internet from an extended cognition perspective (Clark and Chalmers 1998) and extended knowledge perspective (e.g. Palermos and Pritchard 2013), concluding that online information (in some cases) extends our cognitive system and may count as extended knowledge. ${ }^{3}$ Smart's descriptive analysis is insightful and I am largely in agreement with it, but in this paper the focus is more on how we should interact with the Internet, not whether it extends our minds or knowledge-based.

Finally, epistemologists have also analysed the relation we have to Internet search engines, pointing out two potentially undesirable epistemic consequences: (1) confirmation bias due to personalised search results and (2) misleading and inefficient autocompleted search terms. Simpson (2012) has evaluated how well Google Search functions as an epistemic tool. He argues that Google Search and 
other search engines are surrogate experts, playing a rather significant epistemic role. Typically, when we do not know the answer to a question or are looking for some piece of information, we turn to Google. Most search engines, including Google, personalise search results. Google has a database of one's previously used search terms and visited web pages, resulting in a specific informational profile which is unique for each user. Based on that profile, it ranks web pages resulting in a search engine results page (SERP).

So when my neighbour and I both Google the phrase'social epistemology', my SERP is different from hers, because I have previously searched for related terms such as 'epistemology', 'virtue epistemology' and 'intellectual virtues', and visited various web pages related to social epistemology. Web pages I visited previously are prioritised over those I haven't visited and web pages that contain terms I used previously are also prioritised. Simpson argues that personalisation undermines objectivity as it creates 'filter bubbles' that result in confirmation bias. Humans are prone to disagree with and scrutinise information that goes against our existing beliefs and we tend not to scrutinise information that confirms our existing beliefs. Due to personalisation, web pages that fit or are consistent with our existing beliefs are prioritised over those that do not.

If one turns off personalisation, the ranking is determined by an algorithm called PageRank. Google writes:

PageRank works by counting the number and quality of links to a page to determine a rough estimate of how important the website is. The underlying assumption is that more important websites are likely to receive more links from other websites.

A web page will rank highly if many other sites link to it. So, its rank is determined in relation to a network of other websites. Note that this does not necessarily mean that a highly ranking website contains true or accurate information: just because many hyperlinks point towards a website, is no guarantee that it contains epistemically useful information. Also, empirical research using eye-tracking technology has shown that college students implicitly trust Google's ranking in that they prefer to click on links in higher positions even when the abstracts are less relevant to the task at hand (Pan et al. 2007). This shows that page ranking, like personalisation, can be epistemically undesirable.

Miller and Record (2016) point out that Google's autocomplete system may, in some cases, lead us to the wrong path of enquiry. When typing your search term into Google's search bar, it suggests (in real time) two terms that you have previously used and two terms that other people in your local area have used. When you are searching for a term that you have not used before, Google suggests four terms that have been used by people in your area. Sometimes this is helpful as it draws attention to (popular) search queries that one might have otherwise neglected. In other cases, however, it suggests terms that are wrong and misleading and may nudge one into a wrong path of enquiry. For example, when I search ${ }^{4}$ for the term 'vaccines' (a term I had not used before, so all four suggestions are based on what people in my area have searched for), Google suggests the following phrases 'vaccines cause autism', 'vaccines Australia', 'vaccines revealed' and 'vaccines for Vietnam'. The last three suggestions could potentially be helpful, but the first might put a naïve and uninformed user on an epistemically detrimental path.

\section{Online Intellectual Virtues and Vices}

\subsection{Internet Literacy Skills}

Commenting on Internet access, Duncan Pritchard points out that'access to information is of little use if one lacks the cognitive skills to interpret this information and sift the accurate information from the inaccurate, and the epistemically useful information from the epistemically useless' $(2013,237)$. In this section, I explore how virtue epistemology can help Internet users to evaluate and determine which online information is epistemically useful and epistemically useless.

How would an intellectually virtuous person go about finding the answer to the following question: 'What happened to the dinosaurs?' Many online inquiries start with search engines, typically Google 
Search. Google's search engine is an extremely helpful epistemic tool for curious people. But only if you know how to use it well, can it satisfy your curiosity and informational needs. Lynch (2016) gives an example of how search engines sometimes suggest and prioritise false and misleading information. Google Search provides a'featured snippet' at the top of the search results page, when you ask it a question. When Lynch searched for 'What happened to the dinosaurs?', consider Google's featured snippet:

The Bible gives us a framework for explaining dinosaurs in terms of thousands of years of history, including the mystery of when they lived and what happened to them. Dinosaurs are used more than almost anything else to indoctrinate children and adults in the idea of millions of years of earth history. (Lynch 2016, 66)

Due to search engine optimisation, creationists manipulated Google's algorithms such that information on their website was top-ranked for this question. As this example shows, Google's algorithms can be manipulated fairly easily and so we should be cautious with accepting the information in featured snippets as true.

As outlined above, Google builds up a personal profile of your informational preferences and filters search results based on these preferences. In some cases, this may clearly be helpful; however, it can also be epistemically undesirable because it limits users' attention to important bodies of knowledge (Simpson 2012; Miller and Record 2013; but compare Smart and Shadbolt forthcoming). An intellectually open-minded person is willing to consider alternative views, and if these views are more accurate, then she is willing to change her mind. Filter bubbles may reinforce bias and are detrimental to open-mindedness and objectivity. Simpson (2012) therefore suggests to turn off personalisation or to use a different search engine that doesn't personalise such as duckduckgo.com. If one does make use of personalised search results, an intellectually autonomous agent will interpret Google's featured snippets, page ranking and autocompleted search terms with a healthy dose of scepticism. ${ }^{5}$ Also, an intellectually humble person is not just aware of one's onboard cognitive limitations, but ideally also of the limitations of the epistemic tools she is using, implying that such a person should learn these limits.

It is easy to lose track of one's initial search query, but an attentive person will remain focussed on the task; irrelevant images, hyperlinks and websites will not distract her. This, however, is notoriously difficult and requires intellectual discipline and training (see, e.g. Rheingold 2012, Ch 2). As Carr (2011) writes: 'When we go online, we enter an environment that promotes cursory reading, hurried and distracted thinking, and superficial learning' (2011, 115-116). Carr makes a valid point; however, as Rheingold points out:'Attention processes, like muscles can be strengthened through exercise, resulting in measurable changes in brain function' $(2012,62)$. Rheingold suggests mindfulness techniques to help us become more focussed when interacting with the Internet. As part of metacognitive strategies, one can train oneself to recognise distractedness and to force oneself to stay focussed. Another strategy to avoid online distraction is to use software programs (such as Cold Turkey Blocker) that block certain web pages, for example social media. These programs are highly customisable and allow one to block certain web pages at particular times during the day, in that way optimising one's focus. In such cases, attentiveness is offloaded onto a software program.

An intellectually careful person will avoid common mistakes when using Google. Such mistakes may include hastiness such as only clicking on the first-ranked page and not reading other pages as to be able to compare various sources of information. An intellectually thorough person will probe for a deep understanding and will not be satisfied with the first source she encounters. She will keep pursuing her enquiry until she has reached a proper level of understanding. This entails consulting and cross-checking at least a number of different online sources. It may also entail using different search terms such as, for instance, 'Why did the dinosaurs go extinct?'. Or include Boolean operators, for example: 'dinosaurs + extinct-creationism' or 'dinosaurs + extinct + scientific knowledge'.

It takes intellectual courage to search for information in places that are not consistent with one's scientific, cultural, political or religious views. It is unlikely that a dogmatic creationist will look for objective scientific knowledge about evolutionary history on, say, Wikipedia. It is also unlikely that an evolutionary biologist or geologist will look for information on creationists websites. There are, however, people who are forming their beliefs about these matters and haven't made up their mind yet. An open-minded and 
intellectually courageous person will look for information at various online sources and compare and judge their likelihood and validity. She will compare various conflicting sources and use her judgement and critical thinking skills to draw a conclusion. Finally, sometimes it takes a while when you find the answer to your question or query. An intellectually tenacious person will keep searching until she has found what she is looking for. The question: 'What happened to the dinosaurs?' generates 790,000 search results. ${ }^{6}$ It takes some time and patience to sift through and cross-check some of these results.

\subsection{Epistemic Responsibility}

Code (1987) and Montmarquet (1993) argue that epistemic responsibility is the central intellectual virtue; all other intellectual virtues are derived from it. Both authors emphasise the close connection between virtue, agency and responsibility. The notion of responsibility is multifaceted when applied to the Internet. We have a responsibility to use the Internet in an epistemically virtuous way. Anyone who posts information on the Internet has, of course, a responsibility to provide true information, but unfortunately there is a lot of inaccurate, outdated or plain false information on the Internet. For this reason, we have an epistemic obligation to ourselves, as knowers, to interact with the online world in an intellectually virtuous way. Miller and Record (2016) distinguish between epistemic responsibility and epistemic practicability. They write:

An epistemically responsible subject does, inasmuch as she can, what is required of her to bring about true and rational beliefs. Responsibility is delimited in part by role-expectations. Practicability is delimited by the subject's competencies and her technological, ethical, and economic circumstances. Practicability sets an upper limit on responsibility in that a responsible subject need not do more than what is practicable. $(2016$, p. 3)

So, in practice, what an agent is required to do to obtain true beliefs thus depends on one's cognitive capacities and contextual aspects (see also Green 2017). Given that we all have different cognitive capacities and contexts, we also have different degrees of epistemic responsibility. This also applies to the Internet, implying that we do not all have the same level of epistemic responsibility.

Simon (2015) develops the notion of distributed responsibility, arguing that responsibility may be seen as a system's property, rather than a property attributed to an individual Internet user. She argues that in the online world, agents, groups of agents, governments, companies, technological infrastructures and algorithms are entangled in such a way that responsibility attributions are sometimes difficult to make. Usually these components 'cannot be understood in separation but only as socio-technical compounds ... information acquisition and processing involve various hyperconnected agents and institutions' (Simon 2015, 154). In the case of search engines, for example, the SERP is a consequence of one's input, search history and personalisation, Google's algorithm designed by various engineers, search engine optimisation by epistemically malevolent or benevolent actors, and so on. Page ranking is thus the result of many human and artefactual systems. Whilst this may be true, I think this provides an additional reason for developing one's online intellectual virtues. An intellectually virtuous person will want to take responsibility for knowledge acquisition.

My view, which I have detailed in (Heersmink 2017) is that it is difficult to attribute responsibility to distributed systems, in part because it is difficult to hold systems in themselves accountable. This, however, does not mean that Google and other search engines have no epistemic responsibility. Google clearly also has an epistemic responsibility and there are a number of ways in which it can help its users to better understand how the ranking is done, for example by providing a short explanation on the SERP about how the results were ranked (based on personalisation or the PageRank algorithm or both). They could also provide a visual representation of the inbound and outbound link relationships, allowing users to view central and peripheral web pages and trace the connections between web pages to determine the interest and relevance of a web page (Pan et al. 2007). 


\subsection{Virtues and Selfhood}

Lastly, cultivating and improving (online) intellectual virtues is important not just because it is epistemically beneficial for one's information-seeking behaviours, but also because such cognitive virtues are an important part of one's selfhood. Linda Zagzebski points out that 'A virtue is a deep quality of a person, closely identified with her selfhood' $(1996,104)$. The subjective experience of our cognitive agency and deploying our intellectual virtues is often deeply meaningful to us and largely defines who we are as persons (Heersmink 2016). Our identities are deeply tied up with our cognitive skills. Therefore, such virtues have instrumental value in that they are for something (that is, being truth-conducive and minimalising error), but they also have intrinsic value (that is, they are valuable in themselves; we often enjoy utilising our cognitive apparatus for its own sake). As outlined in Section 2, intellectual virtues have an affective dimension. Pursuing one's epistemic goals typically causes some level of pleasure, fulfilment and sometimes even excitement. A genuinely curious person often enjoys learning about the world and when she uses the Internet to learn some new fact, she feels rewarded. For these reasons, it is important that we aim to be intellectually virtuous, as it makes us better thinkers and helps us reach our full potential as persons.

Some of the instrumental value of Internet literacy skills are socio-economic. Internet literacy skills are a positional good (Hirsch 1977), that is, something that gives an agent a benefit over others that lack those skills. In our information society, many jobs (including those in R\&D, finance, policy-making, communication, journalism and many others) require us to use the Internet. An agent who has well-developed Internet literacy skills has a clear economic and professional advantage. However, from a distributive justice point of view, we should ensure that everyone in society has the same Internet literacy skills, or at the very least an equal chance to develop such skills. Optimising our information-seeking behaviours has instrumental value not just for individuals, but also for organisations and society at large (Choo 2016).

\section{Education}

'Technological education will be crucial if human-machine cooperation is to enrich and humanise rather than restrict and alienate' (Clark 2003, 183). Given the significant role the Internet plays in our cognitive and epistemic practices, it is important that we learn to use it in an epistemically virtuous way from the outset. That is to say, schools and universities should include online intellectual virtues in their curriculum. Baehr $(2013)$ and Pritchard $(2013,2014)$ convincingly argue that education should aim not just at spoon-feeding students facts, but also at fostering intellectual virtues. Baehr (2015a) already is an excellent educational tool to help teach students general intellectual virtues. The analysis in this paper extends Baehr's work as to include online intellectual virtues or Internet literacy skills. In relation to the goals of education, Pritchard points out that 'focussing on the real-world situations that citizens encounter - situations that are these day laden with technology - is entirely the right approach for our educational policies to take' $(2014,3)$. I fully agree with Pritchard here. If many epistemic situations in the twenty-first century involve information technology, then we should educate students such that they can use information technology in an epistemically beneficial way (Kotzee forthcoming). Heather Battaly (2016) suggests that intellectual virtues can be taught as part of undergraduate courses in logic or critical thinking. Likewise, universities could (or perhaps should) include Internet literacy skills in such courses. Or even better, schools and universities should design courses exclusively devoted to Internet literacy skills.

Currently, the Internet literacy skills of most people (in both Western and non-Western cultures) are underdeveloped. Based on their empirical work on mapping Internet skills of the Dutch population, Alexander van Deursen and Jan van Dijk conclude that their 'results strengthen the findings that the original digital divide of physical Internet access has evolved into a divide that includes differences in skills to use the Internet' $(2010,893)$. They (2014) also point out that only $28 \%$ of the European population learns (some of) their Internet skills in formal education and $57 \%$ by self-study, mainly trial 
and error, which is much less efficient than formal study. So, there seems to be an important task for educators at primary, secondary and tertiary level to teach pupils and students Internet literacy skills. Howard Rheingold's (2012) book, Net smart: How to thrive online, is a useful resource in this regard. It gives suggestions for training your attention, evaluating online information, participating in online communities such as Wikipedia, and making the best of online collective intelligence such as Amazon's book recommendation system.

A reviewer pointed out that the Internet evolves rapidly and so the epistemic skills needed to interact with the Internet in an intellectually virtuous way are time and context-dependent (see also Simpson 2012). Intellectual virtues that are relevant today may be less relevant in, say, 10 to 20 years. Internet literacy (like computer literacy in general) is thus a constant, lifelong process. Partly for this reason, it is important to educate students across all educational levels to be intellectually virtuous and independent, critical thinkers, because these skills will benefit them for the rest of their cognitive lives.

Furthermore, on my view, we should not just teach students Internet literacy skills, we should also assess these skills. In Denmark, a pilot study (which was subsequently implemented) was conducted in which students were given access to the Internet during their high school and university exams (Knight 2014). Students in a number of subjects, such as Danish language and mathematics, were given access to various Internet websites, but not those that could be used to communicate with other students. Lise Petersen, e-learning project coordinator at the University of Southern Denmark, points out that 'What you want to test is problem-solving and analytical skills, and students' ability to reflect and discuss one particular topic. The skill is discerning between relevant and irrelevant information and then putting it in context' (Cunnane 2011). Students obviously are not allowed to plagiarise and so their submitted work is automatically checked for plagiarism. The Danish case is very much in line with the virtue epistemic approach developed in this paper and should, on my view, be implemented more broadly. Note that I am not saying that the Internet should be accessed in all exams. We also need to assess student's 'knowledge that' (i.e. their propositional knowledge) and so traditional methods of assessment, including written and oral exams, will remain valuable and should be supplemented, not replaced.

Finally, Aristotle argues that moral virtues are learned through formal education, examples and practice. Battaly points out that the structure of responsibilist virtues is analogues to moral virtues, 'both sorts of virtues are acquired dispositions of appropriate action, motivation, emotion, and perception' (2016, 173). Due to their similar structure, intellectual virtues can be acquired in an analogous way as moral virtues (Zagzebski 1996). The following three steps from Battaly are helpful:'(1) use formal instruction to explain the responsibilist virtues; (2) use exemplars to further elucidate individual responsibilist virtues; (3) provide opportunities to practice identifying virtuous actions, emotions, and motivations' (Battaly 2016, 174). The analysis in this paper, can be helpful as an exemplar of using the Internet in an epistemically virtuous way. This exemplar and various others, together with formal instruction and opportunities to practice these skills, are a good starting point for students to develop their Internet literacy skills.

\section{Conclusion}

The Internet is the most extensive and powerful source of information developed in human history, deeply transforming our epistemic practices. In order to use it in an epistemically virtuous way, we need to cultivate and deploy several intellectual virtues and avoid some vices. Whilst an epistemically virtuous use of the Internet will not guarantee that one will acquire true beliefs, understanding or even knowledge, it will strongly improve one's information-seeking behaviours. This is important because it makes us better, well-informed thinkers, and because our virtues are essential to our selfhood. For these reasons, there is an important role for educators to teach and assess these virtues as part of formal school and university curricula, perhaps as part of critical thinking courses. The analysis done in this paper can be used as an exemplar in such education. 


\section{Notes}

1. A reviewer helpfully pointed out that there is a body of work in computer science that is concerned with issues of provenance (Moreau 2010). The application of such work to the Web may be relevant to future forms of epistemic evaluation.

2. However, as a reviewer pointed out, one potentially undesirable aspect of the Internet for scientific research is citation counts. There is a risk that this lead to a rather select group of scientific ideas and findings gaining prominence over more unusual or maverick ideas. This may not be to the overall good of the scientific community.

3. See also, Carter and Gordon (2017) for an analysis of online information in relation to extended mind and extended knowledge approaches.

4. This search was done on 29 June 2017 in Sydney, Australia.

5. A reviewer pointed out that the real challenge for virtuous Internet-use seems to be knowing who to defer to in terms of identifying reliable authority. Indeed, being intellectually autonomous does not mean that one cannot ask others for advice. One may, for example, have read something on a medical webpage but still ask one's doctor whether the information is correct and the source reliable.

6. This search was done on 8 May 2017. A reviewer rightly points out that this figure will vary across time, and given that search results are personalised, it may also differ per user.

\section{Acknowledgements}

I would like to thank J Adam Carter, Orestis Palermos and Mog Stapleton for inviting me to present this paper at a colloquium at the philosophy department of the University of Edinburgh, as well as the audience for helpful feedback. I also like to thank Paul Smart, Robert Clowes, John Sutton, and Simon Knight for helpful discussions on the philosophical dimensions of the Internet.

\section{Disclosure Statement}

No potential conflict of interest was reported by the author.

\section{Notes on Contributor}

Richard Heersmink is a lecturer in philosophy at Macquarie University in Sydney. He has a BSc in Biology (Saxion Hogeschool), an MA in Philosophy of Science, Technology \& Society (University of Twente), and a PhD in Philosophy of Cognitive Science (Macquarie University). His research is located at the intersection of philosophy of cognitive science, philosophy of technology, and neuroethics. He is particularly interested in the ways technology transforms memory, cognition, and the self, as well as the normative implications of these transformations at an individual and cultural level. His work has appeared in Philosophical Studies, Synthese, Philosophical Explorations, Review of Philosophy and Psychology, Phenomenology and the Cognitive Sciences, Neuroethics, and various other journals.

\section{References}

Baehr, J. 2011. The Inquiring Mind: On Intellectual Virtues and Virtue Epistemology. Oxford: Oxford University Press.

Baehr, J. 2013. "Educating for Intellectual Virtues: From Theory to Practice." Journal of Philosophy of Education 47 (2): $248-262$. Baehr, J. 2015a. Cultivating Good Minds: A Philosophical and Practical Guide to Educating for Intellectual Virtues.

Baehr, J. 2015b. "The Four Dimensions of an Intellectual Virtue." In Moral and Intellectual Virtues in Western and Chinese Philosophy, edited by C. Mi, M. Slote, and E. Sosa, 86-98. London: Routledge.

Battaly, H. 2008. "Virtue Epistemology." Philosophy Compass 3 (4): 639-663.

Battaly, H. 2016. "Responsibilist Virtues in Reliabilist Classrooms." In Intellectual Virtues and Education: Essays in Applied Virtue Epistemology, edited by J. Baehr, 163-187. London: Routledge.

Carr, N. 2011. The Shallows: What the Internet is Doing to Our Brain. New York: W.W. Norton \& Company.

Carter, J. A., and E. Gordon. 2017. "Googled Assertion." Philosophical Psychology 30 (4): 486-497. doi:10.1080/09515089.2 017.1285395.

Choo, C. W. 2016. The Inquiring Organization: How Organizations Acquire Knowledge and Seek Information. Oxford: Oxford University Press.

Clark, A. 2003. Natural-born Cyborgs: Minds, Technologies, and the Future of Human Intelligence. Oxford: Oxford University Press.

Clark, A., and D. Chalmers. 1998. "The Extended Mind." Analysis 58: 7-19.

Code, L. 1987. Epistemic Responsibility. Hanover: University Press of New England and Brown University Press. 
Cunnane, S. 2011. "The Danish Gambit: Online Access, Even during Exams." Accessed www.timeshighereducation.com/ news/the-danish-gambit-online-access-even-during-exams/416090.article

van Deursen, A., and J. van Dijk. 2010. "Internet Skills and the Digital Divide." New Media \& Society 13 (6): 893-911.

van Dijk, J., and A. van Deursen. 2014. Digital Skills: Unlocking the Information Society. New York: Palgrave MacMillan.

Greco, J., and J. Turri. 2011. “Virtue Epistemology." In Stanford Encyclopedia of Philosophy, edited by N. Zalta. Accessed https:// plato.stanford.edu/entries/epistemology-virtue/

Green, A. 2017. The Social Contexts of Intellectual Virtue: Knowledge as a Team Achievement. London: Routledge.

Greenfield, S. 2014. Mind Change: How Digital Technologies Are Leaving Their Mark on Our Brains. London: Rider Books.

Heersmink, R. 2016. "The Internet, Cognitive Enhancement, and the Values of Cognition." Minds \& Machines 26 (4): 389-407.

Heersmink, R. 2017. "Distributed Cognition and Distributed Morality: Agency, Artifacts, and Systems." Science \& Engineering Ethics 23 (3): 431-448.

Hirsch, F. 1977. Social Limits to Growth. London: Routledge.

Knight, S. 2014. "Finding Knowledge: What is It to 'Know' When We Search?" In Society of the Query Reader: Reflections on Web Search, edited by R. König and M. Rasch, 227-238. Amsterdam: Institute of Network Cultures.

Kotzee, B. Forthcoming. Cyborgs, Knowledge and Credit for Learning. In Extended Epistemology, edited by J. A. Carter, A. Clark, J. Kallestrup, S. O. Palermos, and D. Pritchard. Oxford: Oxford University Press.

Lynch, M. 2016. The Internet of Us: Knowing More and Understanding Less in the Age of Big Data. New York: W.W. Norton and Company.

Michaelian, K., and S. Arango-Muñoz. Forthcoming. "Collaborative Memory Knowledge: A Distributed Reliabilist Perspective." In Collaborative Remembering: Theories, Research, Applications, edited by M. Meade, C. B. Harris, P. van Bergen, J. Sutton, and A. J. Barnier. Oxford: Oxford University Press.

Miller, B., and I. Record. 2013. "Justified Belief in a Digital Age: On the Epistemic Implications of Secret Internet Technologies." Episteme 10 (2): 117-134.

Miller, B., and I. Record. 2016. "Responsible Epistemic Technologies: A Social-Epistemological Analysis of Autocompleted Web Search." New Media \& Society. doi:10.1177/1461444816644805.

Montmarquet, J. 1993. Epistemic Virtue and Doxastic Responsibility. Lanham, MD: Rowman and Littlefield.

Moreau, L. 2010. "The Foundations for Provenance on the Web." Foundations and Trends in Web Science 2 (2-3): 99-241.

Palermos, O., and D. Pritchard. 2013. “Extended Knowledge and Social Epistemology." Social Epistemology Review and Reply Collective 2 (8): 105-120.

Pan, B., H. Hembrooke, T. Joachims, L. Lorigo, G. Gay, and L. Granka. 2007. “In Google We Trust: Users' Decisions on Rank, Position, and Relevance." Journal of Computer Mediated Communication 12 (3): 801-823.

Pritchard, D. 2013. “Epistemic Virtue and the Epistemology of Education." Journal of Philosophy of Education 47 (2): $236-247$.

Pritchard, D. 2014. "Virtue Epistemology, Extended Cognition, and the Epistemology of Education." Universitas: Monthly Review of Philosophy and Culture 478: 47-66.

Rheingold, H. 2012. Net Smart: How to Thrive Online. Cambridge, MA: MIT Press.

Roberts, R. C., and W. J. Wood. 2007. Intellectual Virtues: An Essay in Regulative Epistemology. Oxford: Oxford University Press.

Simon, J. 2015. "Distributed Epistemic Responsibility in a Hyperconnected Era." In The Onlife Manifesto: Being Human in a Hyperconnected Era, edited by L. Floridi, 145-159. Dordrecht: Springer.

Simpson, D. 2012. “Evaluating Google as an Epistemic Tool." Metaphilosophy 43 (4): 426-445.

Smart, P. Forthcoming. "Emerging Digital Technologies: Implications for Extended Conceptions of Cognition and Knowledge." In Extended Epistemology, edited by J. Carter, A. Clark, J. Kallestrup, S. O. Palermos, and D. Pritchard. Oxford: Oxford University Press.

Smart, P., R. Clowes, and R. Heersmink. 2017a. "Minds Online: The Interface between Web Science, Cognitive Science, and the Philosophy of Mind." Foundations and Trends in Web Science 6 (1-2): 1-234.

Smart, P., R. Heersmink, and R. Clowes. 2017b. "The Cognitive Ecology of the Internet." In Cognition Beyond the Brain: Computation, Interactivity and Human Artifice, edited by S. Cowley and F. Vallee-Tourangeau, 251-282. Dordrecht: Springer.

Smart, P., and N. Shadbolt. Forthcoming. "The World Wide Web." In Routledge Handbook of Applied Epistemology, edited by J. Chase and D. Coady. New York: Routledge.

Thagard, P. 2001. "Internet Epistemology: Contributions of New Information Technologies to Scientific Research." In Designing for Science: Implications from Everyday, Classroom, and Professional Settings, edited by K. Crowley, C. Schunn, and T. Okada, 415-434. Mahwah: Erlbaum.

Zagzebski, L. 1996. Virtues of the Mind: An Inquiry into the Nature of Virtue and the Ethical Foundations of Knowledge. Cambridge: Cambridge University Press. 